\title{
Н.В. Лукоянов
}

\section{КОРПОРАТИВНЫЕ БЕЗДОКУМЕНТАРНЫЕ ЦЕННЫЕ БУМАГИ В ПРАВЕ ИСПАНИИ}

\begin{abstract}
Аннотация. Настоящая статья посвящена анализу правового регулирования корпоративных бездокументарных ценных бумаг в праве на примере Испании. В правовой науке России практически отсутствуют исследования корпоративных бездокументарных ценных бумаг зарубежных государств. Однако механизм регулирования общественных отношений, возникающих по поводу корпоративных бездокументарных ценных бумаг в гражданском и торговом обороте Испании, представляет интерес для российского права. Усложняющийся торговый оборот и правила нормативных актов Европейского союза, имплементированные в национальное законодательство, дают толчок появлению новых видов корпоративных ценных бумаг, не известных ранее испанскому праву (отзывные акции, привилегированные корпоративные паи). Однако правоприменительная практика свидетельствует о том, что надежная правовая защита инвесторов, которые вкладывают свои средства в такие финансовые инструменты, до сих пор не обеспечена.

Ключевые слова: ценные бумаги, бездокументарные ценные бумаги, корпоративные ценные бумаги, акции, облигации, гибридные ценные бумаги, право Испании, акционерные общества, отзывные акции, привилегированные корпоративные паи.
\end{abstract}

Д ля рассмотрения правового регулирования корпоративных бездокументарных ценных бумаг требуется четко очертить объект исследования. вастоящее время в понятие «корпоративный» (исп. corporativo) может вкладываться, по крайней мере, два смысла.

Во-первых, в праве присутствует традиционная позиция, нашедшая отражение в российской и испанской цивилистике, согласно которой под «корпоративной» ценной бумагой понимается ценная бумага, предоставляющая владельцу право на участие в управлении обществом. Принимая во внимание указанное определение, самую категоричную позицию по данному вопросу в российской науке занимает И.Н. Бутина: «Акция является единственной корпоративной ценной бумагой, т. е. ценной бумагой, удостоверяющей право членства в хозяйственном, а точнее - акционерном обществе» ${ }^{1}$.

Во-вторых, сам термин «корпоративный» в словосочетаниях «корпоративное право», «корпоративный спор», получил известную интерпретацию в отечественном праве. По мнению авторов учебника «Корпоративное право», подготовленного кафедрой предпринимательского права МГУ, «Корпорация в широком понимании - юридическое лицо (коммерческая или некоммерческая организация), основанное по принципу участия (членства)»².

Термин «корпоративный» в аналогичном значении используют и экономисты, например, Я.М. Миркин

\footnotetext{
Бутина, И.Н. Правовая сущность современной акции как ценной бумаги// Правоведение. - 2006. - № 6. С. 76.

2 Корпоративное право: учеб. для студентов вузов, обучающихся по направлению «Юриспруденция» / отв. ред. И.С. Шиткина. - М.: Волтерс Клувер, 2007. С. 7.
}

понимает под корпоративными ценными бумагами «фондовые инструменты, выпускаемые предприятиями и организациями» ${ }^{3}$. Авторы книги «Корпоративные ценные бумаги как инструмент инвестиционной привлекательности компаний» высказывают сходную позицию: «Корпоративные ценные бумаги - это ценные бумаги, эмитентом которых выступают коммерческие фирмы ${ }^{4}$.

Таким образом, по нашему мнению, для целей настоящего исследования под термином «корпоративная бездокументарная ценная бумага» необходимо понимать эмиссионную ценную бумагу, выпущенную в бездокументарной форме коммерческой организацией.

Проблематика корпоративных ценных бумаг, представленных в виде записей на счетах, разработана в Испании на высоком уровне. Как отмечается в испанской юридической литературе, это заслуга Государственной комиссии Испании по рынку ценных бумаг, которая провела тщательную работу, направленную на повышение финансовой грамотности населения, в том числе в сфере бездокументарных корпоративных ценных бумаг 5 .

Правовая доктрина и инвестиционная практика выделяет следующие виды корпоративных бездокументарных ценных бумаг в Испании: а) акции; б)

3 Миркин Я. М. Ценные бумаги и фондовый рынок. М., 1995. C. 79.

4 Асаул, А. Н. Корпоративные ценные бумаги как инструмент инвестиционной привлекательности компаний / А. Н. Асаул, М. П. Войнаренко, Н. А. Пономарева, Р. А. Фалтинский: под ред. д.э.н., профессора А. Н. Асаула. - СПб: АНО «ИПЭВ», 2008. C. 93.

http://www.cnmv.es/portalinversor/ 
долговые корпоративные ценные бумаги с постоянной доходностью; в) «гибридные» корпоративные ценные бумаги.

Акция (acción). В отличие от правовой системы РФ, законодательство Испании (Переработанный текст “Закона Испании о торговых обществах" 2010 года) предусматривает, что правом выпускать акции обладает не только акционерное общество (исп. Sociedad Anónima - S.A.), но и коммандитное товарищество на акциях (исп. Soceidad en comandita por acciones - S. Com. por A.). Закон прямо запрещает выпускать акции обществам с ограниченной ответственностью (исп. Sociedad de responsabilidad limitada - S.R.L. $)^{6}$.

Акции представляют собой пропорциональную часть уставного капитала соответствующего торгового общества (коммерческой организации). Статус акционера предоставляет держателям акций ряд прав: имущественные (получение дивидендов и части капитала общества при его ликвидации) и личные, в испанской доктрине, называемые политическими «políticos» (участие в принятии решений предприятия, которые должны одобряться общим собранием акционеров).

Законодательство предусматривает возможность выпуска как документарных, так и бездокументарных акций (ст. 92 Закона о торговых обществах). Статья 113 Закона о торговых обществах предусматривает, что документарные акции могут быть именными или на предъявителя, а ст. 118 закрепляет требование, в соответствии с которым бездокументарные акции могут быть только именными. Помимо того, закон устанавливает, что только в форме записей на счетах выпускаются акции обществ, котируемых на организованном рынке ценных бумаг.

Статья 90 Закона о торговых обществах определяет, что акция является неделимой. Так как ценные бумаги рассматриваются испанской доктриной в качестве вещей, то логичен вывод, что акция является вещью неделимой.

В уставе общества должно фиксироваться, в том числе, количество акций, на который разделен уставный капитал, и их номинальная стоимость (она должна быть одинаковой у акций одной категории). В «Комментарии к правовому регулированию торговых обществ» ${ }^{7}$, выпущенном под редакцией Rodrigo Uría, Aurelio Méndez и Manuel Olivencia, делается вывод, с которым нужно согласиться: функция акции заключается в том, что она является уставной мерой участия лица в обществе.

6 BOE número 265 de 5/11/2003, páginas 39220 a 39252.

7 Comentario al régimen legal de las sociedades mercantiles. Dirigido por: Rodrigo Uría, Aurelio Menéndez y Manuel Olivencia. Tomo IV "Las acciones". Fernando Pantaleón Prieto. P. 17.
Закон делит акции на две категории: предоставляющие право голоса - голосующие (исп. acciones ordinarias) и не предоставляющие право голоса - неголосующие (исп. acciones sin derecho de voto). Акционерные общества и акционерные коммандиты выпускают акции без права голоса номинальной стоимостью, не превышающей половину оплаченного капитала (ст. 98 Закона о торговых обществах).

Держатели неголосующих акций имеют право на получение минимального дивиденда. Его величина может быть постоянной или изменяющейся, что должно быть установлено в уставе общества. Держатели таких акций имеют преимущественное право на получение номинальной стоимости акции при ликвидации общества, а если общество принимает решение о выплате дивидендов, то они выплачиваются держателям акций без права голоса в первую очередь (ст. 99 Закона о торговых обществах).

Особым видом акций, выпускаемым только котируемыми акционерными обществами (исп. Sociedades anónimas cotizadas), являются отзывные акции (или выкупаемые акции - acciones rescatables), которые регулируются ст. Ст. 500, 501 Закона о торговых обществах.

Эта юридическая конструкция была введена в испанское законодательство в 1998 году в связи с имплементацией в правопорядок Второй директивы ЕЭС о координации гарантий, которые требуются в государствах-членах от хозяйственных обществ в значении второго абзаца статьи 58 Договора для защиты интересов их участников и третьих лиц, с целью сделать эти гарантии эквивалентными применительно к учреждению акционерных обществ, а также поддержанию и изменениям их капитала ${ }^{8}$.

Отзывные акции рассматриваются альтернативной обыкновенным акциям при привлечении инвестиций. Отзывные акции погашаются по прошествии установленного срока при соблюдении условий, предусмотренных в решении о выпуске данных ценных бумаг. Причем инициатором этого погашения могут выступать как само общество, так и держатель акций.

Таким образом, в отличие от бессрочного характера обычных акций отзывные акции характеризуются срочностью. Это гарантирует инвестору высокую ликвидность такой ценной бумаги.

Помимо того, отзывные акции предоставляют владельцам и такие права обычных акций, как участие в принятии решений общим собранием, право преимущественного приобретения акций, получение части имущества общества при его ликвидации.

Решение о выпуске отзывных акций должно быть принято общим собранием акционеров с соблюдением процедуры по увеличению уставного капитала.

\footnotetext{
8 http://eur-lex.europa.eu/LexUriServ/LexUriServ. do?uri=CELEX:31977L0091:ES:NOT
} 
Условия выкупа акций должны быть прямо предусмотрены в решении о выпуске отзывных акций. Такое решение должно предусматривать субъектов, которые имеют право выкупать ценные бумаги. Этими субъектами могут быть общество, иные акционеры или как общество, так и акционеры. В случае если правом выкупа обладает только общество, то выкуп должен быть осуществлен по прошествии трех лет с момента выпуска отзывных акций.

Цена, по которой акции будут выкупаться, закрепляется в решении о выпуске и должна быть определенной или определимой. Погашение отзывных акций, как и любых акций, сопровождается уменьшением уставного капитала.

Таким образом, отзывные акции являются корпоративными бездокументарными ценными бумагами, основными достоинствами которых являются их срочный характер и ликвидность.

\section{Долговые корпоративные ценные бумаги с постоянной доходностью (valores de renta fija)}

Долговые корпоративные ценные бумаги с постоянной доходностью являются ценными бумагами, которые закрепляют срочное долговое обязательство предприятия. Они приносят фиксированный доход или доход, исчисляемый по формуле, установленной в решении о выпуске.

К долговым корпоративным бездокументарным ценным бумагам, приносящими постоянный доход, относятся облигации (исп. obligaciones).

Акционерное общество и акционерная коммандита могут выпускать облигации (эмиссионные ценные бумаги) и иные ценные бумаги, которые опосредуют отношения по займу (ст. 401 Закона о торговых обществах). Общество с ограниченной ответственностью не может выпускать облигации или иные оборотоспособные эмиссионные ценные бумаги (ст. 402 Закона о торговых обществах).

Облигации, выпускаемые в соответствии с испанским законодательством, делятся на обеспеченные и необеспеченные. Статья 404 Закона о торговых товариществах устанавливает, что обеспечением облигаций может быть ипотека, залог движимого имущества, залог ценных бумаг с передачей или без передачи последних на хранение кредитной организации, гарантия государства, автономного сообщества, провинции или муниципального образования, поручительство кредитной организации или общества взаимного гарантирования (исп. sociedad de garantía recíproca).

Общество может выпускать облигации без обеспечения в пределах суммы уставного капитала и резервных средств, отраженных в балансовом отчете за финансовый год. Это правило не распространяется на выпуск вышеупомянутых обеспеченных облигаций (ст. 405 указанного закона).

Облигации выпускаются в документарной и бездокументарной формах. Документарные облигации могут быть именными и на предъявителя, а бездокументарные в соответствии с требованиями Закона о рынке ценных бумаг - только именными.

Облигации делятся на конвертируемые и неконвертируемые. Общество имеет право выпустить облигации, конвертируемые в акции, в том случае, если общее собрание акционеров определит способы и основания конвертации и примет решение об увеличении уставного капитала на сумму облигационного займа.

\section{«Гибридные» корпоративные бездокументарные ценные бумаги (valores híbridos)}

Гибридные ценные бумаги - это финансовые инструменты, обладающие свойствами как обыкновенных акций, так и инструментов займа (облигаций). Целью создания «гибридных» ценных бумаг является повышение доходности акций и снижения рисков облигаций. Они направлены на удовлетворение потребностей как акционеров, так и кредиторов: акционеры вкладывают свои средства с целью получения дивидендов и повышения стоимости акций, а займодатели ожидают выплаты процента за пользование денежными средствами и возвращения основной суммы займа в срок, установленный договором.

Гибридные ценные бумаги позволяют повысить доходность за счет отказа от права на участие в управлении обществом и повысить ликвидность инструмента, снижая риски. Помимо того, нормативные акты, которые допускают возможность выпуска данных ценных бумаг, устанавливают, что полученные при выпуске «гибридов» денежные ресурсы учитываются в собственных средствах предприятия, а для целей налогообложения они рассматриваются как обязательство, что позволяет достичь оптимального для общества использования привлеченного финансирования9.

Выпуск подобных финансовых инструментов разрешен законодательством Испании. На испанском языке они называются "participaciones preferentes" (ст. 2 Закона о рынке ценных бумаг). В российском праве нет аналога данной конструкции, как нет и эквивалента этого понятия в русском языке. Однако для целей настоящего исследования мы считаем целесообразным назвать эту ценную бумагу «привилегированные кор-

\footnotetext{
9 Miguel Ángel Villacorta Hernández. Acciones rescatables y otros híbridos financieros societarios. Algunos aspectos jurídicos (sustantivos, financieros y contables). Tesis doctoral. Universidad Carlos III de Madrid. 2011. P. 127.
} 
поративные паи». Выбор такого варианта перевода продиктован тем, что в российской правовой действительности существует ценная бумага, называемая «инвестиционный пай», однако, слово "participaciones" указывает на принадлежность к корпорации, поэтому логично перевести его как «корпоративный пай».

Правовое регулирование «привилегированных корпоративных паев» содержится в третьем дополнительном положении Закона Испании о юридическом режиме передвижения капитала и внешнеэкономических транзакциях и о некоторых мерах по борьбе с отмыванием денег № 19 от 4 июля 2003 года ${ }^{10}$. Этим положением внесены изменения в Закон Испании о коэффициентах инвестиций, собственных средствах и обязанностях по предоставлению информации финансовыми посредниками № 13 от 25 мая 1985 года ${ }^{11}$.

В условиях постигшего испанскую экономику кризиса последних лет испанские суды рассмотрели ряд споров, связанных с привилегированными корпоративными паями. В решении суда Первой инстанции провинции Сантандер говорится, что «правовая природа данной ценной бумаги является неясной ${ }^{12}$. Очевидно, это свидетельствует о некоторых неточностях самого закона, а также о недостаточности правоприменения.

Привилегированные корпоративные паи выпускаются только кредитными организациями, являющимися резидентами Испании или резидентами других стран ЕС, кроме тех, которые не признаны оффшорными. Привилегированные корпоративные паи выпускаются в бездокументарной форме и являются именными ценными бумагами.

Они предоставляют некумулятивное (то есть ненакапливающееся) право на получение фиксированного дохода, выплата которого производится в случае, если общество или группа обществ получила прибыль, достаточную для выплаты дохода по привилегированным корпоративным паям. В то же время данный вид ценных бумаг не предоставляет владельцам ни право участвовать в принятии решений общества, ни права на преимущественное приобретение акций. В случае ликвидации кредитной организации привилегированные корпоративные паи не предоставляют право на возврат номинальной стоимости.

Номинальная стоимость выпускаемых «привилегированных долей» не должна превышать $30 \%$ основных собственных средств кредитной организации.

Привилегированные корпоративные паи являются бессрочными. Однако эмитент может принять решение погасить их по прошествии 5 лет с момента выпуска. Такие решения принимаются многими испанскими кредитными организациями, например, банками Santander, BBVA, Popular, la Caixa, Bankia, Caixa Catalunya ${ }^{13}$. При погашении привилегированных корпоративных паев происходит их конвертация в обыкновенные акции, автоматически общество увеличивает свой уставный капитал и полностью погашает задолженность перед кредиторами, предоставляя им права на участие в управлении организацией.

Судебная практика свидетельствует о том, что привилегированные корпоративные паи носят алеаторный (то есть рисковый) характер, так как их доходность зависит от экономических показателей деятельности кредитной организации ${ }^{14}$.

Право Испании признает существование корпоративных бездокументарных ценных бумаг, которые существуют и в праве Российской Федерации (акции и облигации), однако, современные тенденции развития испанского законодательства свидетельствуют о расширении числа документов, принадлежащих к корпоративным ценным бумагам, за счет введения новых институтов (отзывные акции, привилегированные корпоративные паи). До настоящего момента не существует единообразной практики регулирования отношений, которые возникают в связи с выпуском и обращением таких ценных бумаг. Поэтому перед испанским законодателем и судебной системой стоит задача обеспечить эффективную защиту инвесторов, вкладывающих свои средства в такие ценные бумаги.

\section{Библиографический список:}

1. Ley de Medidas de Reforma del Sistema Financiero de 22 de noviembre de 2002, entrada en vigor, con la salvedad indicada, el 24 de noviembre de 2002, BOE número 281 de 23/11/2002, páginas 41273 a 41331.

2. Real Decreto Legislativo $1 / 2010$, de 2 de julio, por el que se aprueba el texto refundido de la Ley de Sociedades de Capital, BOE núm. 161 de 03/07/2010, páginas 58472 a 58594.

3. Real Decreto 116/1992, de 14 de febrero, sobre Representación de valores por medio de anotaciones en cuenta y Compensación y Liquidación de Operaciones bursátiles, BOE número 44 de 20/2/1992, páginas 5964 a 5974.

\footnotetext{
10 BOE número 160 de 5/7/2003, páginas 26166 a 26174.

11 BOE número 127 de 28/5/1985, páginas 15639 a 15643.

12 Juzgado de Primera Instancia número 1 de Santander. Sentencia 223/2012, de 29 de noviembre.
}

\author{
13 http://www.elboletin.com/index. \\ php? noticia $=55052 \&$ name $=$ economia \\ 14 Juzgado de Primera Instancia número 1 de Santander. \\ Sentencia 223/2012, de 29 de noviembre.
}


4. Juzgado de Primera Instancia número 1 de Santander. Sentencia 223/2012, de 29 de noviembre.

5. García-Pita y Lastres, J. Derecho de Títulos-Valores (Parte General) / J. García-Pita y Lastres. Santiago de Compostela: Adavira editora, 2006. $939 \mathrm{p}$.

6. Martínez-Echevarría y García de Dueñas, A. Valores mobiliarios anotados en cuenta. Concepto, naturaleza y régimen jurídico / A. Martínez-Echevarría y García de Dueñas. Madrid: Editorial Mariano Otero, 1997. 335 p.

7. Pantelon Prieto, F. Las acciones (Tomo IV del Comentario al régimen legal de las sociedades mercantiles) / F.Pantelon Prieto. Madrid: Civitas, 1992. 157 p.

8. Tapia Hermida, A. J. Sociedades Anónimas Cotizadas y Ofertas Públicas de Adquisición / A.J.Tapia Hermida. Madrid: La ley (grupo Wolters Kluwer), 2012. 314 p.

9. Miguel Ángel Villacorta Hernández. Acciones rescatables y otros híbridos financieros societarios. Algunos aspectos jurídicos (sustantivos, financieros y contables). Tesis doctoral. Universidad Carlos III de Madrid. 2011. P. 127.

10. Diaz Moreno, A. La Prenda de Anotaciones en Cuenta// Revista Crítica de Derecho Inmobiliario. Núm. 603.1991. Pag. 355-441.

11. Акопян О.А. Правовое регулирование финансового рынка в США в кризисные периоды развития // Журнал зарубежного законодательства и сравнительного правоведения. - 2011. - 2. - С. 62-68.

12. Асаул, А.Н. Корпоративные ценные бумаги как инструмент инвестиционной привлекательности компаний / А.Н. Асаул, М.П. Войнаренко, Н.А. Пономарева, Р.А. Фалтинский: под ред. д.э.н., профессора А.Н. Асаула. СПб: АНО «ИПЭВ», 2008. - 288 с.

13. Асаул, А.Н. Корпоративные ценные бумаги как инструмент инвестиционной привлекательности компаний / А.Н. Асаул, М.П. Войнаренко, Н.А. Пономарева, Р.А. Фалтинский: под ред. д.э.н., профессора А.Н. Асаула. СПб: АНО «ИПЭВ», 2008. - 288 с.

14. Бутина, И. Н. Правовая сущность современной акции как ценной бумаги// Правоведение. - 2006. - № 6. С. 76.

15. Грекова И.Ю. Правовое регулирование рынка ценных бумаг // NB: Финансовое право и управление. - 2013. 3. - C. 53-62. URL: http://www.e-notabene.ru/flc/article_2880.html

16. Корпоративное право: учеб. для студентов вузов, обучающихся по направлению "Юриспруденция"/ отв. ред. И.С. Шиткина.-М.: Волтерс Клувер, 2007. - 648 с.

17. Корпоративное право: учеб. для студентов вузов, обучающихся по направлению "Юриспруденция"/ отв. ред. И.С. Шиткина.-М.: Волтерс Клувер, 2007. - 648 с.

18. Миркин Я.М.. Ценные бумаги и фондовый рынок. - М.: Перспектива, 1995. - 600 с.

19. Миркин Я.М.. Ценные бумаги и фондовый рынок. - М.: Перспектива, 1995. - 600 с.

20. Правовой портал Европейского союза-http://eur-lex.europa.eu/.

21. Сайт издательской группы “Elboletin.com"-http://www.elboletin.com/

22. Сайт Официального государственного бюллетеня Испании (Boletín Oficial de Estado)-http://www.boe.es/).

23. Татаринцева К.Н. Ограничения прав участников рынка ценных бумаг в процессе эмиссии акций: законодательство и судебная практика // Актуальные проблемы российского права. - 2013. - 3. - С. 269-275.

\section{References (transliteration):}

1. Akopyan O.A. Pravovoe regulirovanie finansovogo rynka v SSHA v krizisnye periody razvitiya // Zhurnal zarubezhnogo zakonodatel'stva i sravnitel'nogo pravovedeniya. - 2011. - 2. - C. 62-68.

2. Asaul A.N. Korporativnye tsennye bumagi kak instrument investitsionnoj privlekatel'nosti kompanij / A.N. Asaul, M.P. Vojnarenko, N.A. Ponomareva, R.A. Faltinskij: pod red. d.eh.n., professora A.N. Asaula. - SPb: ANO «IPEHV», 2008. $-288 \mathrm{~s}$.

3. Butina, I. N. Pravovaya sushhnost' sovremennoj aktsii kak tsennoj bumagi // Pravovedenie. - 2006. - № 6. S. 76 .

4. Grekova I.YU. Pravovoe regulirovanie rynka tsennykh bumag // NB: Finansovoe pravo i upravlenie. - 2013. - 3. C. 53-62. URL: http://www.e-notabene.ru/flc/article_2880.html

5. Korporativnoe pravo: ucheb. dlya studentov vuzov, obuchayushhikhsya po napravleniyu "Yurisprudentsiya"/ otv. red. I.S. SHitkina. - M.: Volters Kluver, 2007. - 648 s.

6. Mirkin YA.M. Tsennye bumagi i fondovyj rynok. - M.: Perspektiva, 1995. $-600 \mathrm{~s}$.

7. Pravovoj portal Evropejskogo soyuza-http://eur-lex.europa.eu/.

8. Sajt izdatel'skoj gruppy “Elboletin.com"-http://www.elboletin.com/

9. Sajt Ofitsial'nogo gosudarstvennogo byulletenya Ispanii (Boletín Oficial de Estado)-http://www.boe.es/).

10. Tatarintseva K.N. Ogranicheniya prav uchastnikov rynka tsennykh bumag v protsesse ehmissii aktsij: zakonodatel'stvo i sudebnaya praktika // Aktual'nye problemy rossijskogo prava. - 2013. - 3. - C. 269-275. 